\title{
A Case Report of Multiple Aseptic Facial and Spinal Abscesses in a 45-Year-Old with Inflammatory Bowel Disease
}

\author{
Matthew Zheng, MD \\ Thomas Jefferson University Hospital, matthew.zheng@jefferson.edu \\ Kristen Jackson, MD \\ Thomas Jefferson University, kristen.jackson@jefferson.edu \\ Gloria Francis, MD \\ Thomas Jefferson University, gloria.francis@jefferson.edu \\ Bolin Niu, MD \\ Thomas Jefferson University, bolin.niu@jefferson.edu
}

Follow this and additional works at: https://jdc.jefferson.edu/tmf

Part of the Gastroenterology Commons, and the Internal Medicine Commons

Let us know how access to this document benefits you

\section{Recommended Citation}

Zheng, MD, Matthew; Jackson, MD, Kristen; Francis, MD, Gloria; and Niu, MD, Bolin (2016) "A Case Report of Multiple Aseptic Facial and Spinal Abscesses in a 45-Year-Old with Inflammatory Bowel Disease," The Medicine Forum: Vol. 17 , Article 16.

DOI: https://doi.org/10.29046/TMF.017.1.017

Available at: https://jdc.jefferson.edu/tmf/vol17/iss1/16

This Article is brought to you for free and open access by the Jefferson Digital Commons. The Jefferson Digital Commons is a service of Thomas Jefferson University's Center for Teaching and Learning (CTL). The Commons is a showcase for Jefferson books and journals, peer-reviewed scholarly publications, unique historical collections from the University archives, and teaching tools. The Jefferson Digital Commons allows researchers and interested readers anywhere in the world to learn about and keep up to date with Jefferson scholarship. This article has been accepted for inclusion in The Medicine Forum by an authorized administrator of the Jefferson Digital Commons. For more information, please contact: JeffersonDigitalCommons@jefferson.edu. 


\title{
A Case Report of Multiple Aseptic Facial and Spinal Abscesses in a 45-Year-Old with Inflammatory Bowel Disease
}

\author{
Matthew Zheng, MD, Kristen Jackson, MD, Gloria Francis, MD, and Bolin Niu, MD
}

\section{INTRODUCTION}

Sterile abscess syndrome is a rarely described entity that is often associated with auto-inflammatory disorders. Although clinically similar to septic abscesses, sterile abscesses are known to be unaffected by antibiotic regimens and instead highly sensitive to steroids. The association of sterile abscesses with inflammatory bowel disease has been well-described. The majority of sterile abscess syndromes described in the literature are intraabdominal abscesses related to a primary gastrointestinal inflammatory disease. We describe a unique case of extra-abdominal sterile abscess syndrome associated with inflammatory bowel disease presenting as facial and paraspinal lesions.

\section{CASE PRESENTATION}

We present a case of a 45 -year-old male with a history of asthma, eczema and ulcerative colitis currently on mesalamine, who initially presented to an outside hospital with complaints of facial and back pain. For three months, he experienced thoracic and lumbar back pain and, two weeks ago, developed right-sided facial lesions causing pain. In the emergency department, these lesions were determined to be abscesses and were drained. He was discharged on doxycycline and a short course of prednisone taper. At that time, he did not have any intestinal manifestations of ulcerative colitis.

After discharge, however, the abscesses increased in size, associated with worsening pain. He began experiencing high fevers with progressive back pain. Laboratory results this time were notable for leukocytosis of $18.7 \times 10 \wedge 3 / \mathrm{LL}$ (74\% neutrophils, 16\% lymphocytes, $8 \%$ monocytes, 1.8\% eosinophils). While admitted, the patient remained intermittently febrile with purulent drainage from his right facial abscesses despite administration of broad spectrum antibiotics (Vancomycin and Zosyn).

Given no improvement on antibiotics, a biopsy of a facial abscess was performed. The appearance of the abscesses was concerning for sterile abscess syndrome versus Sweet's syndrome. Biopsy results revealed suppurative inflammation with neutrophilic dermatosis, a finding commonly seen in patients with inflammatory bowel disease. Periodic acid Schiff stain, acid-fast baclli stain and gram stain failed to reveal any organisms. His abscess cultures were significant for typical skin flora, coagulase negative Staphylococcus and Propionibacterium acnes.
The patient was diagnosed with sterile abscess syndrome, given that the lesions were very atypical of Sweet's Syndrome in characteristic and more consistent with a collection rather than a localized skin manifestation. He was immediately started on $60 \mathrm{mg}$ prednisone once a day with improvement in his symptoms. Due to significant erythema around the abscess sites, there was concern for concurrent cellulitis and he completed a seven-day course of antibiotics, initially Vancomycin which was narrowed to Augmentin.

While hospitalized, the patient's ongoing back pain was evaluated to determine whether it was also a manifestation of the underlying inflammatory bowel disease. MRI of the cervical spine was performed which demonstrated prevertebral and paravertebral enhancement and abscesses along the lower cervical and upper thoracic spine. Cultures from the spinal abscesses were negative for any organisms. While evaluating the facial abscesses, a CT scan of the facial structures incidentally revealed an abscess in the cervicothoracic region.

With steroid treatment, the patient's facial abscesses and back pain improved significantly. He was discharged with instructions to complete a prednisone taper and follow-up MRI of the face and spine in three weeks.

\section{DISCUSSION}

Sterile abscess syndrome is a rarely described entity associated with auto-inflammatory disorders. Other nomenclature for this pathology include aseptic abscesses syndrome and corticosteroid-sensitive aseptic abscesses. First described by Andre et al. in 1995, the syndrome is a diffuse inflammatory condition characterized by deep, well-defined sterile collections of polymorphonuclear neutrophils associated with pain, high grade fevers, and leukocytosis. They are not responsive to antibiotic treatment, but are highly sensitive to corticosteroid therapy.

Sterile abscess syndrome equally affects young adults of both sexes with a mean age of onset at thirty years. The most frequently affected areas are the spleen, abdominal lymph nodes, liver and pancreas. Cases involving the lung, brain, muscle, and pharynx have also been described in the literature, though much less commonly. This case is unique for its unusual area of involvement which has not previously been described. 
A thirty patient retrospective study by Andre et al. on aseptic abscesses revealed several important clinical points regarding this condition. The mean duration of symptoms until diagnosis was 4.7 months. Twenty-seven of twenty-nine patients had abscesses in the spleen. Twenty-two (70\%) had elevated white blood cell and neutrophil counts. Twenty-one patients had inflammatory bowel disease, which preceded, occurred concomitantly, or presented as a result of the abscesses. Six of the patients had neutrophilic dermatosis, which was also present in our patient.

For treatment, all patients received steroid therapy. Thirteen (43\%) were given additional immunosuppressive therapy with TNF-alpha inhibitors usually as a result of relapse despite being on steroids. This disease entity carries a high rate of relapse. In the study by Andre et al, eighteen of the thirty patients (60\%) experienced one or more relapses. There were no deaths reported that were attributed to aseptic abscesses. In two patients, relapses occurred while on immunosuppressive therapy. The other sixteen patients had relapses while their corticosteroid treatment was being tapered and they were not receiving additional immunosuppressive therapy.

After review of the literature, further questions remain to be explored. Sterile abscess syndrome is an under-recognized entity in auto-inflammatory diseases, as evidenced by the observed delay in diagnoses. The unique locations of this patient's abscesses lends credence to the possibility that these entities can occur anywhere in the body. It remains to be determined if abdominal imaging should be ordered as a standard of care, given the extensive description of splenic involvement in the literature. The rate of relapse in this condition is high; clinical questions regarding whether immuno-modulating medications should be administered to prevent such relapses should be studied further

\section{KEY POINTS}

Aseptic abscesses present a major, complication of inflammatory bowel disease that mimic the presentation of bacterial abscesses. In these cases, differentiating the two entities is critical as steroids are critical treatment for aseptic abscesses. Most cases present as intra-abdominal collections but, as seen in our case, these sterile abscesses can potentially occur anywhere in the body. Long-standing treatment remains controversial, but high dose steroids remain the most effective method of initial treatment. Further investigation is required to assess how to differentiate these entities from bacterial collections and how to minimize recurrences.

\section{REFERENCES}

1. Andre M, Aumaitre $O$, et al. Aseptic systemic abscesses preceding diagnosis of Crohn's disease by three years. Dig Dis Sci 1995; 40: 525-7

2. Andre M, Piette J, et al. Aseptic Abscesses: A Study of 30 Patients With or Without Inflammatory Bowel Disease and Review of the Literature. Medicine 2007; $86: 145-61$

3. Andre M, Piette $\mathrm{J}$ et al. Retropharyngeal and splenic aseptic abscesses treated with prednisone and cyclophosphamide in a patient with ulcerative colitis Dig Dis Sci 2003; 48; 1193-5

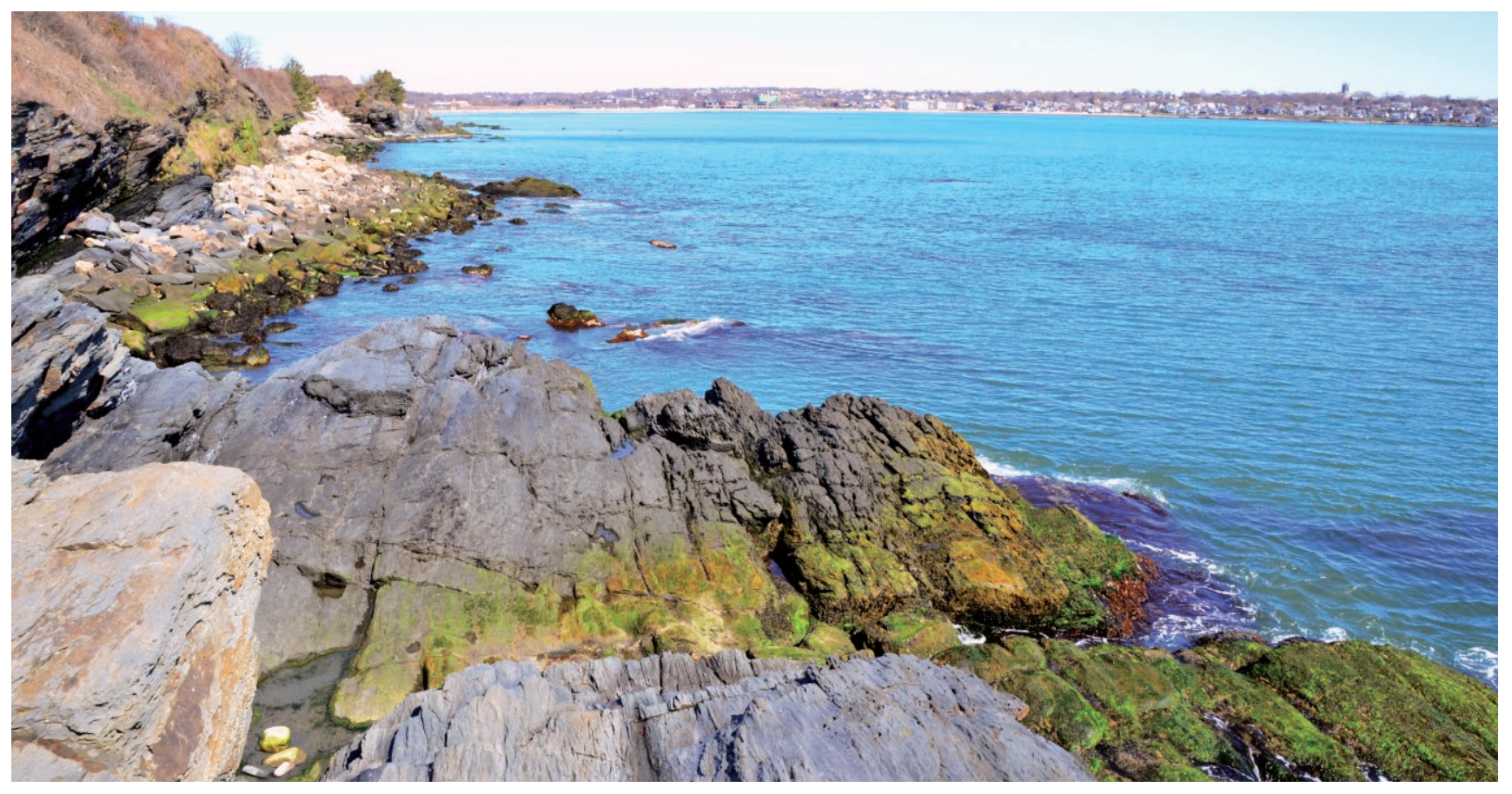

Anusha G. Govind, MD 